Journal of Urban and Regional Analysis, vol. XII, 2, 2020, p. 117 - 143

https://doi.org/10.37043/JURA.2020.12.2.1

\title{
STRUCTURAL CHANGES IN JAPAN'S URBAN SYSTEM FROM 1990 TO 2010
}

\author{
Kai LIU ${ }^{1}$, Tamba Sahr DAUDA ${ }^{2}$ \\ ${ }^{1}$ Fuzhou University, Fuzhou, China, ${ }^{2}$ University of Tsukuba, Tsukuba, Japan
}

\begin{abstract}
An urban system is a group of cities acting in close cooperation with one other. An examination of the factors of change in an urban system at the national scale remains to be done, given data limitations and research issues (e.g., scale, boundary). This study aims to clarify the spatiotemporal pattern of Japan's urban system (JUS) and then to elucidate the characteristics of change and the related factors, based on an inter-regional travel survey conducted in Japan from 1990 to 2010, as well as numerous official censuses. The results demonstrate the entire system's compactness, the dominance of the metropolises and the local system's bipolarization under the hierarchical structure of JUS, with the establishment of hub cities and the development of infrastructure during the two decades from 1990 to 2010. Finally, this study explains the factors of change with consideration of socio-economic characteristics and inter-regional interaction.
\end{abstract}

Key Words: inter-cities' linkage, geo-spatial multivariate analysis, Japan's urban system.

\section{Introduction}

An urban system can be regarded as a group of cities acting in close cooperation with each other. There are particular channels for persons, logistics, information, energy, capital, etc., flowing between the cities, whereby each city is supplied with the necessary "nutrients" for growth and each regional area is supplemented with mutual functions (Murayama 2000). The interaction between the cities brings about the expression of various regional attributes as the characteristics of the city group. Measuring this interaction is vital to understanding the formation and evolution of the urban system. Moreover, modeling the space of flow among cities and measuring its relationship with regional indexes in the context of an urban system bring insight on interpreting the cities' positions in a changing urban system.

Considering the achievements in research on national urban systems, numerous studies have elucidated the urban system pattern in terms of inter-cities' flow, such as the formation of national urban system and its changing process (Murayama 1982), the patterns of spatial interaction and the hierarchical structures (Song et al. 2008), and the connectivity of Chinese cities in the world city network (Derudder et al. 2013, Yao et al. 2018). Considering the background of China's high-development of infrastructure, Wang (2010) identified the intercities' container transport hubs and their distribution-aggregation pattern in a Chinese urban system, and Sun (2016) revealed the relationship between the China's hierarchical urban system and high-speed railway (HSR) network planning. Besides, the change of population scale (Wang et al. 2005), telecommunication flows (Dong et al. 2014), and innovation connection (Zhou et al. 2017) are also used to model the urban system.

Spatial scales adopted in empirical studies of urban systems (networks) are hierarchical and multilayer, consisting of three levels: international (Smith and Timberlake 2001, Guimerà et al. 2005, Choi et al. 2006, Wang et al. 2015), national (Murayama 1982, Song et al. 2008, Yu et al. 2008, Wang 2010, Leng et al. 2011, Zhen et al. 2012, Derudder et al. 2013, Sun 2016) and regional urban systems (Wang et al. 2005, Dong et al. 2014, Zhou et al. 2017). For example, at the international scale, some studies have focused on the world city network (WCN) and its 
hierarchy (Smith and Timberlake 2001), some have compared the WCN in terms of different flow elements (Choi et al. 2006) and some have investigated the international linkage and role of the WCN by specifically targeting one country (Wang et al. 2015).

Investigating the hierarchical structure of an urban system can help us better understand its formation, change and reshaping processes. Measuring the scale of the urbanization index (e.g., GDP, population, commuting flow) provides justification for identifying the centrality of a city within an urban system. At the municipal (intra-city) scale, urban compactness can be reflected in terms of the balance of the availability of work with the number of residents, the advantages of the degree of accessibility and the dominance of urban resources. Between urban areas and suburban areas, the imbalances in population migration, the gap in jobhousing choices and people's need and willingness for commuting activities have led to the bipolarization of urban development levels within metropolitan areas.

Differently, at the inter-city scale (e.g., province, country, international), the inter-regional traffic infrastructure can not only affect the compactness of the whole urban system, but also the segmentation-aggregation, uniformity-diversity, coordination-independence of the secondary (sub)urban system, shaping and controlling smaller local parts of the individual cities' secondary systems. Cities with fewer urban resources and potential tend to be marginalized by cities that hold central positions within the urban systems; this is also regarded as a reason for the bipolarization (or multipolarization) of the urban system. How to mitigate such bipolarization and how to find balance in such development toward the synergetic interaction among central cities and lower-class cities within an urban system must be studied as meaningful issues.

\section{Problem statement, literature review and research purpose}

In this section, the authors will herein reveal the research gap reflected within the field of urban system studies in terms of spatial scale choice, the obtaining of data and the interpretation of change factors, accompanied by a series of literature review. The previous studies include investigations of the formation processes of urban systems and the hierarchical structure of urban systems at different scales. However, most of them used the given administrative divisions as their analysis unit, bringing the problem of territorial heterogeneity due to the boundary, size, etc.

Furthermore, multi-view studies focusing on aspects of controllable scale and carried out with a combined-verified approach have rarely been performed in the field of urban system studies, excluding a handful of references in the research of Sun (2016), for example. The national HSR system forms the basis of the urban network pattern at the national scale, while the inter-urban HSR system satisfies people's travel needs within urban agglomerations at the regional scale (Sun 2016). In the context of Japan's urban study, considering that Japanese aviation system has been dominated by governments, the emergence of other traffic networks (e.g., HSR, highway) can be understood as a reflection of neoliberal policies that stimulated the transportation-oriented development after the late 1990s. For better seeking and realizing the reasonable urban planning for mitigating the problem of overly centralization and local depopulation, Japanese urban planners had reported a series of polices, such as the planning of networked compact cities (cf. the white paper from MLIT 1989-2000), as well as Japanesesuitable division methods of functional urban area, such as daily living sphere (MLIT 1990, 2010), urban employment area (CSIS 2015). As mentioned by Murayama (2000), different factors determined urban systems in different scales and they affected different patterns of diffusion process. Undoubtedly, it is necessary to model the pattern of urban system in terms of different transportation modes, from a comprehensive perspective and at a uniform and reasonable scale in the context of Japan's urban system. More related explanations will be presented in Section 2.1. 
The third example of areas within the field of study that have been ignored so far is the preconceived idea of administrative planning. The urban and the countryside should not be divided with a strict boundary. They are typically mixed within a complex cooperated system. Here, the authors should mention Japan's special administrative planning. Municipalities in Japan consist of thousands of cities, special wards, towns and villages. However, the meaning and scale are completely different from other countries' administrative divisions (e.g., China). Japanese urban planners have strongly promoted a long-term urban policy, such as networked compacted cities, local hub-city conservation, combined metropolises, daily living spheres, etc., in order to face the urban problems of an aging society, depopulation and local recession. The area division adopted by previous studies was mostly based on the traditional administrative boundary. Different from them, this study uses the policy-based division as the spatial unit, defined by MLIT $(1990,2010)$ and supported by Morikawa (1998)'s theory of the daily living sphere. By doing so, the scale bias and the above-mentioned problems can be weakened. About this point, Section 2.1 will introduce in detail the Japan's master plan and guideline policy on the administrative division.

On the other hand, owing to the data shortage and the data inconsistency at the national and international scales, many scholars have preferred to carry out their research on urban systems as constructed by a single kind of flow. Burghouwt et al. (2003) confirmed that the hub-andspoke network of European airlines required a concentration of traffic in a spatiotemporal dimension, and its configuration was described along with the distribution of traffic change. Guimerà et al. (2005) put forth that a city's global role in the aviation network was based on the city's inter-community and intra-community connections; they also suggested that the multicommunity structure of the network leaded to the anomalous value of centrality. Some scholars have analyzed information flows - for example, Sina mico-blog (China's twitter) (Zhen et al. 2012), knowledge flows (Lu and Li 2010, Matthiessen et al. 2010, Zhou et al. 2017) and information communication (Dong et al. 2014) — to model the national urban system.

However, inter-urban interaction retains multiplex channels for moving persons, logistics, information, energy, capital, etc., via mutual functional cooperation (Murayama 2000). Moreover, the passengers' ability to choose the transportation modes and the competition between the different transportation industries may cause distortion in the results of a study of the urban system model. In this paper, the authors analyze Japan's urban system (JUS), using person flow data for all kinds of transportation modes (cf. Section 2.2) and aiming to overtake the data limitations outlined above.

Certainly, there are also many studies that have discussed a regional or national urban system in Japan, like Murayama (1984), Nishihara (1994), and Yokura (2016). Murayama (1984) and Nojiri (1993) investigated patterns of freight flows in Japan, pointing the way to understanding industrial locations and confirming spatial structures of regional economic activities. The relationship between the socio-economic features and the urban system pattern has also been considered at the regional or national scale (e.g., Murayama 1984, Nishihara 1994). However, all of these studies used the traditional administrative boundary as their spatial unit and they used a single type of flow to construct the urban system. Considering this, it is crucial to fill the noted research gap in the context of JUS studies.

The social network analysis is a quantitative analysis method proposed in the field of sociology. Recently, it has been widely used to analyze the flows of international flights, trades or cities' spatial structures and to understand the hierarchy that is formed through the interactions between cities. Globalization and World Cities Research Network (GaWC) has mustered hundreds of publications that analyze the global urban network using this theory, such as Taylor (2004) and Derudder et al. (2003, 2007, 2013), who pioneered a powerful database and approach to understanding the world city network. However, only using producer services or other single variables as the indicators, as in Taylor (2004)'s work, but not taking into 
consideration the functional difference affected by other economic sectors, transportation or industrial flows, the results would potentially be biased or distorted (Lee 2008). Therefore, following the GaWC research group's basic theory and Lee's standpoint, this study modifies the original social network model, carrying out a series of analyses in terms of the connectivity of inter-city linkage and the national centrality of cities, using a high-quality database (1990-2010) from Japan's Government (Government of Japan 1990, 2010).

Urban centrality is a city's essential characteristic in terms of general function, based on which, most cities usually have corresponding particular characteristics that accompany the specific socio-economic, political, and cultural tasks or other human activities taking place there (Wang et al. 2005). Previous studies have attached importance to the modeling of centrality indexes integrated by cities (nodes) and inter-city/-regional relations (links) within the urban system from a shallow viewpoint. However, the consideration of the urban function differentiation (e.g., industry composition, economic status, urban resource facility, etc.) within the urban system is lacking. Most of the research has not paid enough attention to the interpretation of the impact of socio-economic features on this system from the individual-local (e.g., inhabitant attribute, local character) viewpoint.

Changes in the transportation network are not only a requirement of urban socio-economic development, but also a reflection of the changing characteristics of the urban system structures. Although the analysis of the dynamic process of urban systems in respect to the urban function was put forward on a classic theory derived from Christaller's Central Place Theory (Johnston 1982), these above-mentioned papers did not look at the functional interpretation of urban cooperation as a major issue. Wang et al. (2005) mentioned that the dynamic evaluation of the urban system is actually equal to the differential growth process of the city and that the difference in urban function is one of the key factors leading to the change of urban system. Unfortunately, their target area was limited within China's one province. They mapped the spatiotemporal pattern of the hinterland within a regional urban system over the span of fifty years, using private business census data. However, these achievements did not receive further verification (e.g., connecting them to the consideration of socio-economic indexes) because of the lack of data precision; the same was the case with Guo and Bai (1999).

Reviewing previous studies, we found that aside from elucidating the spatial pattern of the urban system, how to clarify the regional development and its related factors has rarely been addressed. Urban systems and their spaces of flow should be studied as being of equal value and importance. Performing multi-view studies that considered the issue of the urban system on a uniform scale by the way of introducing reasonable factors to explain the pattern within the urban system's mutual feedback mechanism, not just those resting on constructing this pattern itself, may bring some unknown research interests. In brief, an examination of the changing processes of the national urban system and the related factors, with consideration for the socio - economic features, is urgently needed to fill this research gap.

Against the above-mentioned backdrop, the purpose of this paper is to clarify the spatiotemporal pattern of the urban system in Japan and then to highlight and elucidate the change mechanisms of JUS and the related factors from 1990 to 2010, based on the interregional travel survey (ITS) in Japan (MLIT 1990, 2010) and numerous other official censuses. The rest of this paper is structured as follows. First, Section 2 focuses on transport infrastructure development and planning in Japan. In addition, Section 2 explains the data production and methodological framework. Then, Section 3 highlights the results of the spatiotemporal pattern of the hierarchical urban system in Japan, and it then reveals the factors causing the changes in JUS using two kinds of multivariate analysis, combined with qualitative investigation. Last, Section 4 summarizes the key findings and conclusions and it reaffirms the originality and significance of the study. 


\section{Methodology}

\section{Introduction of the daily living sphere and transport infrastructure development in the context of Japan's urban planning}

A regional urban system is generally understood as an urban system organized on the regional scale in which a regional hub city plays the pivotal center. On the other hand, a prefectural urban system is organized on a prefectural scale, in which a prefectural capital is generally occupied in the top tier of the urban hierarchy. Differently, because of Japan's situation (narrow territory, special administrative division, etc.), the characteristics of Japan's urban system are reflected on three levels: a national urban system with centralized state power, a regional urban system based on the domain of the prefecture and a daily urban system based on the commuting area gathering its surrounding population (Yokura 2016). Fig. 1 illustrates how to understand the system of the daily living sphere (DLS), its referents (MLIT 2010) and other academic propositions discussed by Morikawa (1998). Furthermore, the arrangement of the DLS as the analysis unit in this study will also be highlighted in this section.

Certainly, other kinds of area division can also be used to model the changing pattern of national urban system, like Martinus et al. (2019) that examined the spatial pattern of industry, commuting and agglomeration to innovation for giving an overview of the development of JUS. However, the DLS used in this context is a kind of policy-based functional area, and this study is using this way of area division to model the pattern of the national urban system of Japan. The change of population, commuting rate and industry structure can affect the spatial pattern of the commuting area or the urban employment area within one DLS. Differently, how these factors drive the change of JUS, what can be seen from the structural change of JUS and how the change can be explained by using this DLS as the analysis unit to model the JUS are the target of this study. Clarifying the spatiotemporal pattern of JUS and elucidating the characteristics of change and the related factors from 1990-2010 require a unified area division in this context, otherwise the dataset of regional indexes cannot be integrated in the same GISbased environment.

The DLS has a size between the domain of the prefecture and the daily commuting area in the context of Japan's urban planning. DLS is generally set up by dividing a prefecture into several areas from the viewpoint of a functional area. A city-region means a regional daily living sphere, which includes a core city and its neighboring rural areas most closely connected with the city both economically and socially. A metropolitan area can be regarded as a kind of nodal region at the DLS level, and the influence of Japan's local core city is well reflected and leading the typical daily human mobility of the DLS in this structure (Morikawa 1998). This paper regards the DLS as another term of conurbation (i.e., a networked compact city) that can be adopted to fit its research purpose. The definition of DLS has taken into account the state of the urban functional cooperation, the preservation of local hub-cities and the promotion of human mobility. Using a DLS as an analytical unit to model JUS is suitable and acceptable for addressing the shortages due to scale problems (i.e., territorial heterogeneity, boundary inconsistency) and cities' functional incompleteness.

Before constructing the pattern of the JUS, it is necessary to highlight the background of transport infrastructure development and planning in Japan during the period from 1990 to 2010, which helps to understand the particularity and practicality in terms of actual situations and policy implementation within JUS. The planning of Japan's transport infrastructure system can be traced back to 1969 with the proposal of a national spatial structure plan presented by the Japanese statesman Kakuei Tanaka ${ }^{1}$ to build the nationwide high-speed railway network, spreading all over the country. Although this policy was difficult to fully realize and it was postponed owing to financial shortage due to the end of a high economic growth period by the 


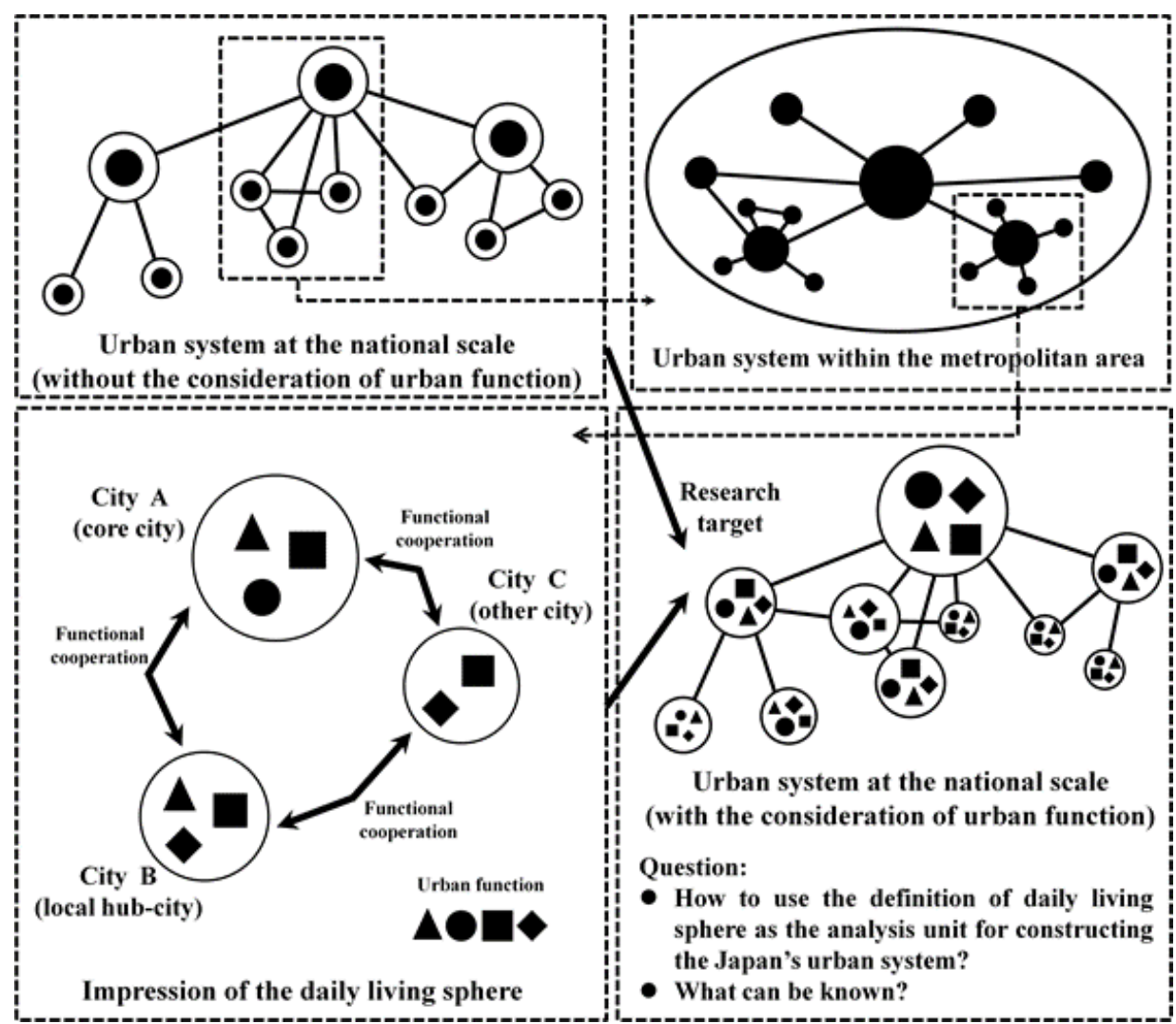

Fig. 1 - The impression of the daily living sphere and how to use it as the analysis unit for constructing the pattern of the JUS

oil crises, deficits and depopulation, it certainly promoted Japan's development of transport infrastructure and it brought with its regional economic booms. The Ministry of Land, Infrastructure and Transport (MLIT) has tried to amend this policy to satisfy passengers' demands and to maintain economic prosperity since the 1980s, after which HSR, airport, railway, highway, subway in (metropolises), Internet and other transport infrastructures began to hold great importance, considering the task of restraining the centralization of the three metropolitan areas (i.e., Tokyo, Nagoya and Osaka) and preserving the domination of regional core cities and other collection centers or transit points. Fig. 2 shows the major transport infrastructure development and planning in Japan from 1990 to 2010, from which some findings will be found to support our results in Section 3.

\section{Data production in a GIS-based environment}

This section highlights data production in a GIS-based environment. First, it is necessary to introduce comprehensive regional indicators for clarifying their impact on the urban system. This paper strives to fill the research gaps noted in the previous section. However, utilizing the data scattered across various resources presents a challenge, as it does coping with the big data storm in the modern loT (Internet of Things) society. Unlike most previous studies that 
shallowly limited the consideration on the pattern identification of the urban system but paid no attention to explore the underlying mechanisms of the impact of the regional feature on the urban system, in this study, many regional attribute variables covering diverse fields, including population, economy, transportation, industrial composition, human facility, etc., are introduced to improve reliability and to provide the project with a multivariate analysis.

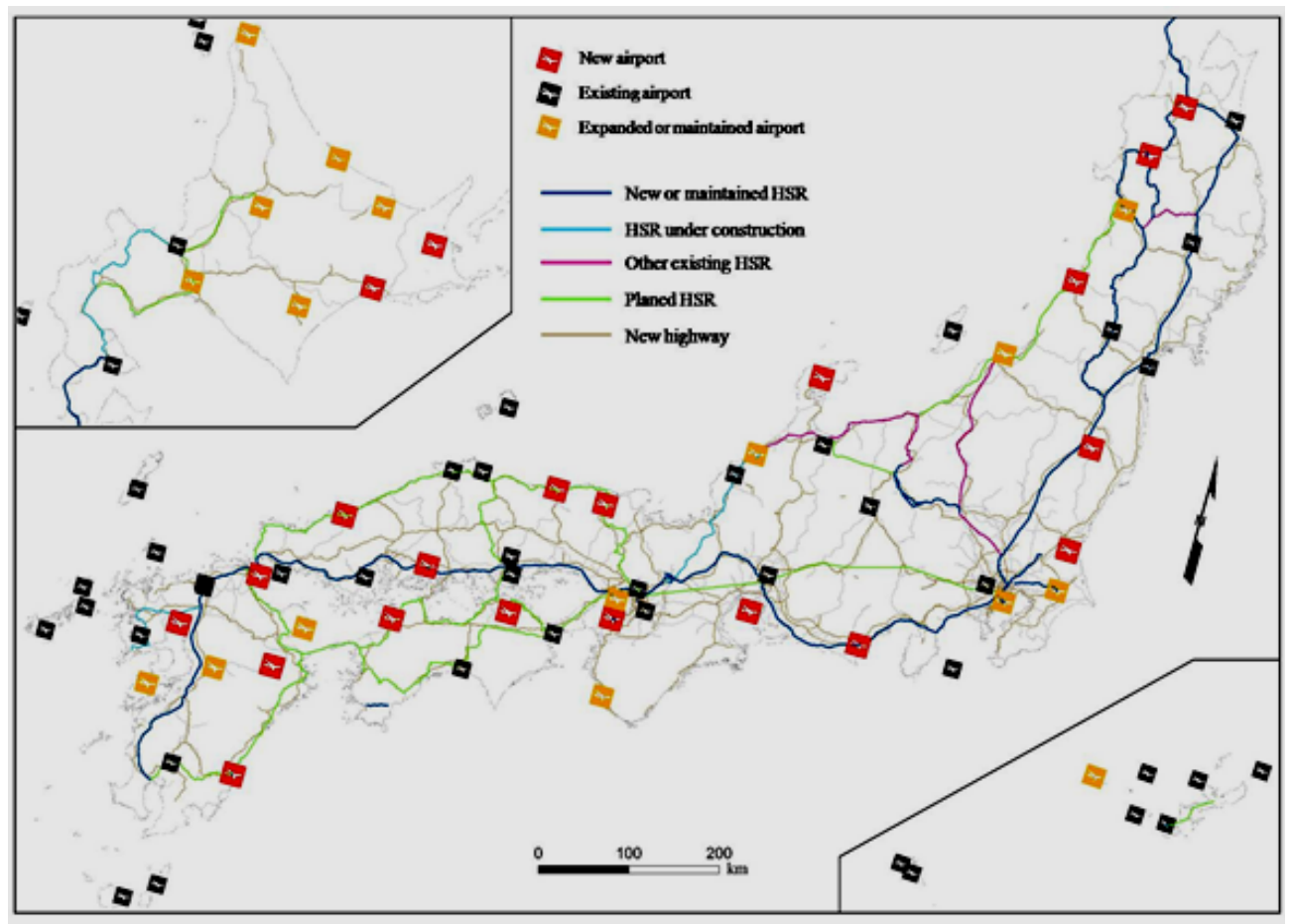

Fig. 2 - Major transport infrastructure development and planning in Japan from 1990 to 2010

Note: Reorganized by the authors based on MLIT (1990, 2010), Land, Infrastructure and Transport White Paper (MLIT 1989-2000), and website information (source: http://www.mlit.go.jp/en/index.html).

For a better understanding of Japan's long-term master plan on infrastructure development, the map focuses on the new HSR, HSR under construction (to 2010), planned HSR (only mentioned in governmental plans) and newly built HSR (during 1990-2010).

As outlined in the previous sections, the approach in this study for measuring JUS formation and change was based on the scale of DLS. That is, all original data has been recalculated by the authors in order to match this scale. The next stage in this paper is an explanation of the Inter-regional Travel Survey (ITS) conducted in Japan from 1990 to 2010, which was carried out as a national project for capturing human mobility in terms of all transportation modes among 207 consistent zones (i.e., DLS). According to MLIT (2010), Japan is divided into 207 zones, mainly based on the urban functional complementation and the mutual intra-regional commuting rate. Moreover, the authors' efforts in data collection and summarization of transportation flows and socio-economic variables over these twenty years are hard but satisfactory. Fig. 3 shows a map of the study area and the regional division, on which the location, ID and place name of each zone can be found. 


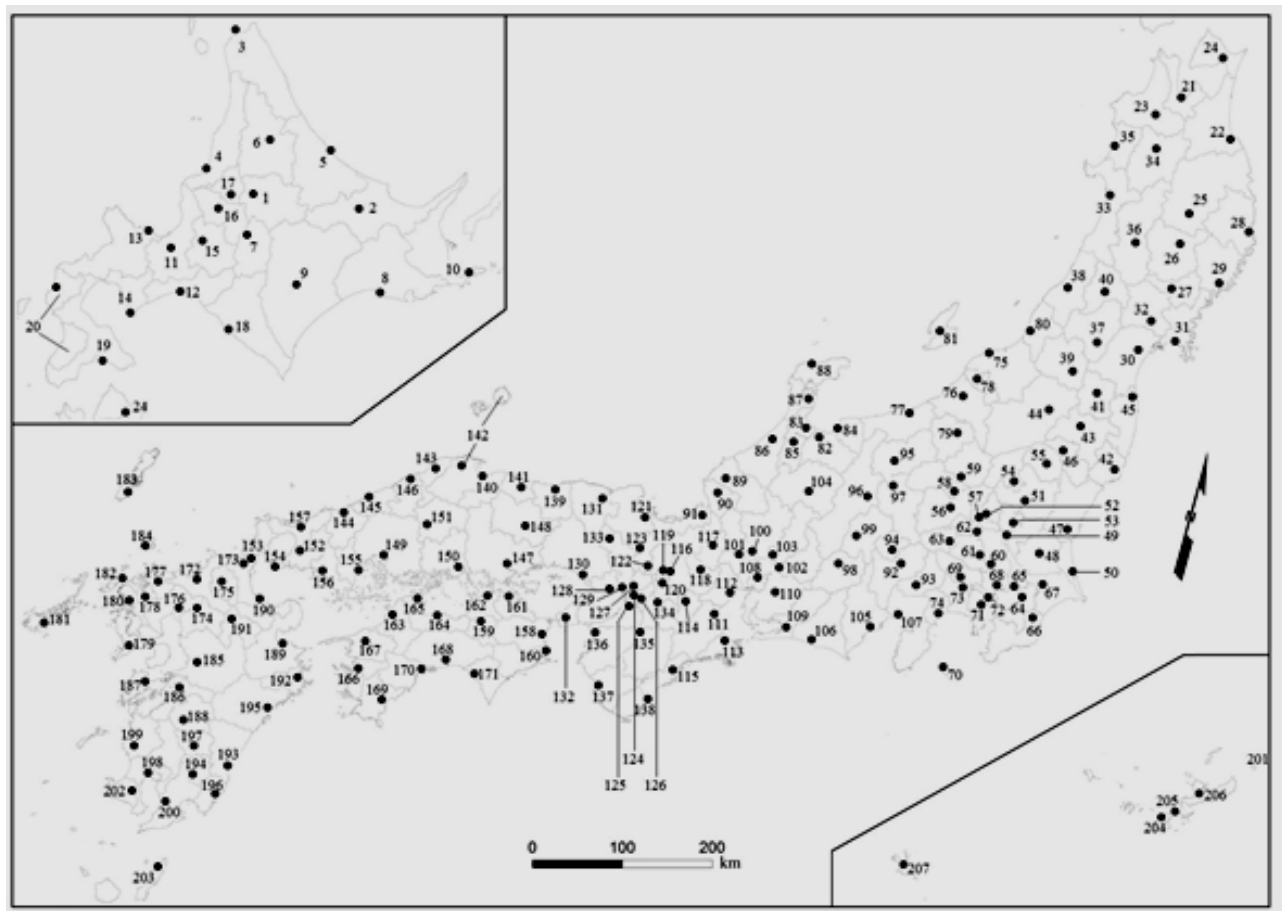

Fig. 3 - Study area and regional division

Note: Dots show the central city of each daily living sphere and the ID corresponds to the place name (omitted here). Datasets of 1990 and 2010 have already been integrated based on the area division of this map

Datasets used in this study are summarized in Table 1. Particularly, the authors integrate all raw data at different scales from multiple sources into one unitary scale - that is, the DLS and then produces the original dataset in a GIS-based environment. By using these data, this study designs a statistical model to demonstrate the relationship between the pattern of JUS and the socio-economic features, following and learning from the achievements of previous studies, such as Murayama (1984) and Nishihara (1994). Note that all census data shown in Table 1 is aggregated on a municipal basis, i.e., Shikuchōson scale ${ }^{2}$, given that the biggest difficulty is the data's inconsistency, this needed to be surmounted. In short, the authors collected the municipality-based raw data (1990 and 2010) from a variety of sources and they integrated them within the same GIS-based table according to its zone code as unique identifier, and then they merged the zones within the same DLS, and it lastly used the summary calculation for obtaining the dataset shown in Table 1. In addition, considering it was necessary to lessen the data bias due to the coexistence of an absolute value and a relative value, all variables $(x)$ have been transformed into standard form, using the formula: .

$$
x=\frac{x-x_{\mathrm{min}}}{x_{\mathrm{m} \Delta x^{-}}-x_{\mathrm{m} i+1}}
$$


Dataset and corresponding sources

\begin{tabular}{|c|c|c|c|c|c|}
\hline ID & Variable & Source & ID & Variable & Source \\
\hline 1 & $\begin{array}{l}\text { Annual passenger } \\
\text { flow (outflow) for } \\
\text { different purposes }\end{array}$ & \multirow{2}{*}{$\begin{array}{l}\text { Inter-regional } \\
\text { Travel Survey in } \\
\text { Japan (MLIT } \\
\text { 1990, 2010) }\end{array}$} & 14 & Rate of in-migrants & $\begin{array}{l}\text { Basic Resident } \\
\text { Register (MIC } \\
1990,2010 \mathrm{a})\end{array}$ \\
\hline 2 & $\begin{array}{l}\text { Annual passenger } \\
\text { flow (inflow) for } \\
\text { different purposes }\end{array}$ & & 15 & $\begin{array}{l}\text { Annual sales of } \\
\text { merchandise }\end{array}$ & \multirow[t]{2}{*}{$\begin{array}{l}\text { Census of } \\
\text { Commerce (METI } \\
1994,2007)\end{array}$} \\
\hline 3 & $\begin{array}{l}\text { Proportion of day- } \\
\text { time population to } \\
\text { night-time popula- } \\
\text { tion }\end{array}$ & \multirow[t]{6}{*}{$\begin{array}{l}\text { Population } \\
\text { Census (MIC } \\
1990,2010 b)\end{array}$} & 16 & $\begin{array}{l}\text { Number of employees } \\
\text { per store }\end{array}$ & \\
\hline 4 & $\begin{array}{l}\text { Commuting rate } \\
\text { outward to prefec- } \\
\text { ture }\end{array}$ & & 17 & $\begin{array}{l}\text { Employment } \\
\text { population }\end{array}$ & \multirow[t]{4}{*}{$\begin{array}{l}\text { Population } \\
\text { Census (MIC } \\
1990,2010 b)\end{array}$} \\
\hline 5 & Population & & 18 & $\begin{array}{l}\text { Employment rate for } \\
\text { primary sector of the } \\
\text { economy }\end{array}$ & \\
\hline 6 & $\begin{array}{l}\text { Percentage of aged } \\
\text { people }(>65)\end{array}$ & & 19 & $\begin{array}{l}\text { Employment rate for } \\
\text { secondary sector of } \\
\text { the economy }\end{array}$ & \\
\hline 7 & Population density & & 20 & $\begin{array}{l}\text { Employment rate for } \\
\text { tertiary sector of the } \\
\text { economy }\end{array}$ & \\
\hline 8 & $\begin{array}{l}\text { Population growth } \\
\text { rate } \\
(+ \text { or }-)\end{array}$ & & 21 & $\begin{array}{l}\text { Number of privately- } \\
\text { owned vehicles }\end{array}$ & $\begin{array}{l}\text { Statistics of } \\
\text { Privately-Owned } \\
\text { Vehicles } \\
\text { (AIRIA 1990, } \\
\text { 2010) }\end{array}$ \\
\hline 9 & $\begin{array}{l}\text { Gross national } \\
\text { income }\end{array}$ & $\begin{array}{l}\text { Report on Pre- } \\
\text { fectural Acco- } \\
\text { unts } \\
\text { (Government of } \\
\text { Japan 1990, } \\
2010 \text { ) }\end{array}$ & 22 & $\begin{array}{l}\text { Number of railway } \\
\text { stations }\end{array}$ & \multirow[t]{5}{*}{$\begin{array}{l}\text { National Land } \\
\text { Numerical } \\
\text { Information } \\
\text { Download Service } \\
\text { (NLNIDS 2010) }\end{array}$} \\
\hline 10 & $\begin{array}{l}\text { Agriculture } \\
\text { population }\end{array}$ & \multirow{2}{*}{$\begin{array}{l}\text { Statistics of } \\
\text { Agricultural In- } \\
\text { come Produced } \\
\text { (MAFF 1990, } \\
\text { 2010) }\end{array}$} & 23 & $\begin{array}{l}\text { Number of cultural } \\
\text { facilities }\end{array}$ & \\
\hline 11 & $\begin{array}{l}\text { Agricultural income } \\
\text { produced }\end{array}$ & & 24 & $\begin{array}{l}\text { Dummy variable of the } \\
\text { isolated island }\end{array}$ & \\
\hline 12 & $\begin{array}{l}\text { Value of shipments } \\
\text { of manufactured } \\
\text { goods }\end{array}$ & \multirow{2}{*}{$\begin{array}{l}\text { Census of Man- } \\
\text { ufacturers } \\
\text { (METI 1990, } \\
2010)\end{array}$} & 25 & $\begin{array}{l}\text { Number of high- } \\
\text { way interchanges }\end{array}$ & \\
\hline 13 & $\begin{array}{l}\text { Number of emplo- } \\
\text { yees per factory }\end{array}$ & & 26 & $\begin{array}{l}\text { Superiority of airport } \\
\text { access }\end{array}$ & \\
\hline
\end{tabular}


The GIS dataset provided by MLIT is updated yearly and is not invariable; thus, the authors have downloaded the 2010 dataset. That is, the dataset for successive years (before 2010) is not available. However, some GIS data, such as the shape-file of railway stations, includes information about the architectural age or usage age. Hence, the authors revised these shapefiles from 2010 and recreated those of 1990 using the GIS technology.

Annual inter-regional passenger flow among the 207 zones quantifies the centrality scale that expresses urban dominance within the entire JUS; this is a kind of long-term inter-regional flow for four different purposes: business, tourism, private affairs and other. Three kinds of transportation indexes - i.e., the ratio of human mobility for each purpose (not including the category of other or unknown) - were calculated for measuring the regional difference of passenger behaviors. It should be noted that ITS data does not include the daily commuting flow, which tends to be more of a short-term intra-regional flow (MLIT 1990, 2010). Thus, another two transportation indexes - i.e., the proportion of daytime population to night-time population and the commuting rate outward to the prefecture - were obtained from the Population Census (MIC 1990, 2010b) and they are introduced to measure an urban center's conglomerated power exerted on its surrounding commuting areas. Variables 1 to 4 correspond to the indexes of the transportation flows.

To explain why each variable is introduced into the analysis process, the research purpose and questions should be reiterated. The variables are not only introduced to model human mobility within JUS (e.g., variables 1 to 4), but also to measure socio-economic attributes within each zone (e.g., variables 5 to 26). Variables 5 to 8 and 14, focusing on the population, percentage of aged people, population density, population growth rate and number of in-migrants, capture the regional population features. Variables 9, 11, 12 and 15 are collected to consider the economic strength of three major industries. Variables 12, 13, 16 and 17 to 20 measure the employment population indexes in three sectors. Variable 21 reflects the vehicle transport capacity. Variables 22, 23, 25 and 26 consider the infrastructure service levels. Variable 24 is the dummy variable for the isolated island, which is an important geographical element. Particularly, the superiority of airport access $\left(S_{i}\right)$ of zone $i$ is calculated by using the form of the gravity model,

$$
S_{i}=\sum_{n} \frac{\operatorname{Ln}\left(\alpha_{+L} x v_{+L}\right)}{d_{i+1}^{2}}
$$

where $a$ is floor area of the airport, $v$ is the annual number of passengers, $n$ is the number of airports, and $d_{i n}$ is the Euclidean distance between the city center of the urban $i$ and airport $n$.

In addition, neglecting the scale bias (partly from the regional differences of size, population, etc.), but giving importance to the avoidance of a collinearity problem, the authors use both absolute variables and rate variables (such as values 3,4 and 5 , and 15, 16 and 17). This is also useful for dividing similar values, or values with collinearity, into different factors. In other words, it might make us to get less monotonous factor results but more changeable results. For example, if using employment rate instead of employment population, value 14 with value 15 17 will terribly cause the problem of collinearity. This influence might be more problematic than the scale problem and thus not acceptable. Sometimes, the factor analysis also provides incorrect results. To avoid this collinearity problem and to consider the scale problem as fully as possible, the authors fully brought into play the potential of different and complex available datasets and they attempted to build a better model by undertaking the variable transformation (both standard transformation and logarithmic transformation), as mentioned above. 


\section{Constructing the pattern of the hierarchical urban system}

In the national urban system, a city's influence indicates its national centrality (NC). This study devised a model for measuring the centrality indexes in JUS by using the ITS dataset, rather than the equation of prestige centrality, following Lee's (2008) approach. Through the values of $\mathrm{NC}$, which city is connected to how many other cities in JUS, what passenger volumes are in a certain city and which connected city has the most volume can be examined. To calculate NC, a city's local centrality and the connectivity of inter-city linkage should first be examined. The equation of local centrality $\left(L_{i}\right)$ is defined as follows:

$$
L_{\mathrm{i}}=\frac{t}{g-1} \times \sqrt{\frac{F_{\mathrm{i}}}{M_{g}}}
$$

where $g$ is the total number of cities (207), $t$ is the number of cities whose passenger flow is directly connected to the city $i$ is higher than zero, $M_{g}$ is the average total flows of all cities calculated as the equation: $\Sigma(O+D) / g$, wherein $O$ and $D$ express the row and column elements within the $207 \times 207$ OD matrix. $F_{i}$ is total summation of inflow and outflow via city $i$.

Here the word "local" isn't a geographical concept but means one part of the whole system, i.e., the limited area formed by the direct-connection relationship between cities. This $L_{i}$ also reflects the city's dominance within the sub-urban system. Next, the connectivity of inter-city linkage $\left(C_{i j}\right)$ is measured according to the following equations:

$$
\begin{gathered}
C_{i j}=\frac{f_{i j}}{m} \times L_{i} \times L_{j}(i \neq j) \\
m=\frac{\sum(O+D)}{r}
\end{gathered}
$$

where $m$ is the average flow of all inter-city linkages, $r$ is how many inter-city linkages have zero-higher number of passenger flows; $f_{i j}$ is the number of the round-trip flow between city and $j$. $C_{i j}$ can be regarded as the product of the weight value of the local centrality of the origin and destination cities. Herein, the $\mathrm{NC}\left(N_{i}\right)$, which implies the city dominance referred to the whole urban system, can be defined as follows:

$$
N_{\mathrm{i}}=\sum_{j=1}^{g}\left\{\frac{f_{\mathrm{ij}}}{m} \times L_{\mathrm{i}} \times L_{j}\right\}=\sum c_{\mathrm{i} j}
$$

This $\mathrm{Ni}$ can be regarded as the total summation of $C_{i j}$, which reflects the dominance of city $i$ referred to the whole urban system. After the calculation of NC, the authors performed hierarchical classification to reveal the spatiotemporal pattern of JUS.

\section{Performing a series of geo-spatial multivariate analyses and the study framework}

This section explains how to apply the socio-economic variables, covering diverse fields in both 1990 and 2010 , to conduct a factor analysis to capture the dynamic regional attributes. Then, the relationships between the hierarchical urban system and the regional functional differences, as well as further mechanisms of change in Japan's urban system and the related factors, are discussed via the canonical analysis. Fig. 4 indicates the study framework.

First, data cleaning and production are performed to obtain a clean OD matrix and table listing. All indexes are loaded into a GIS-based database at the scale of DLS level. Second, through the calculation of the centrality index and the hierarchical classification of NC and inter-regional 


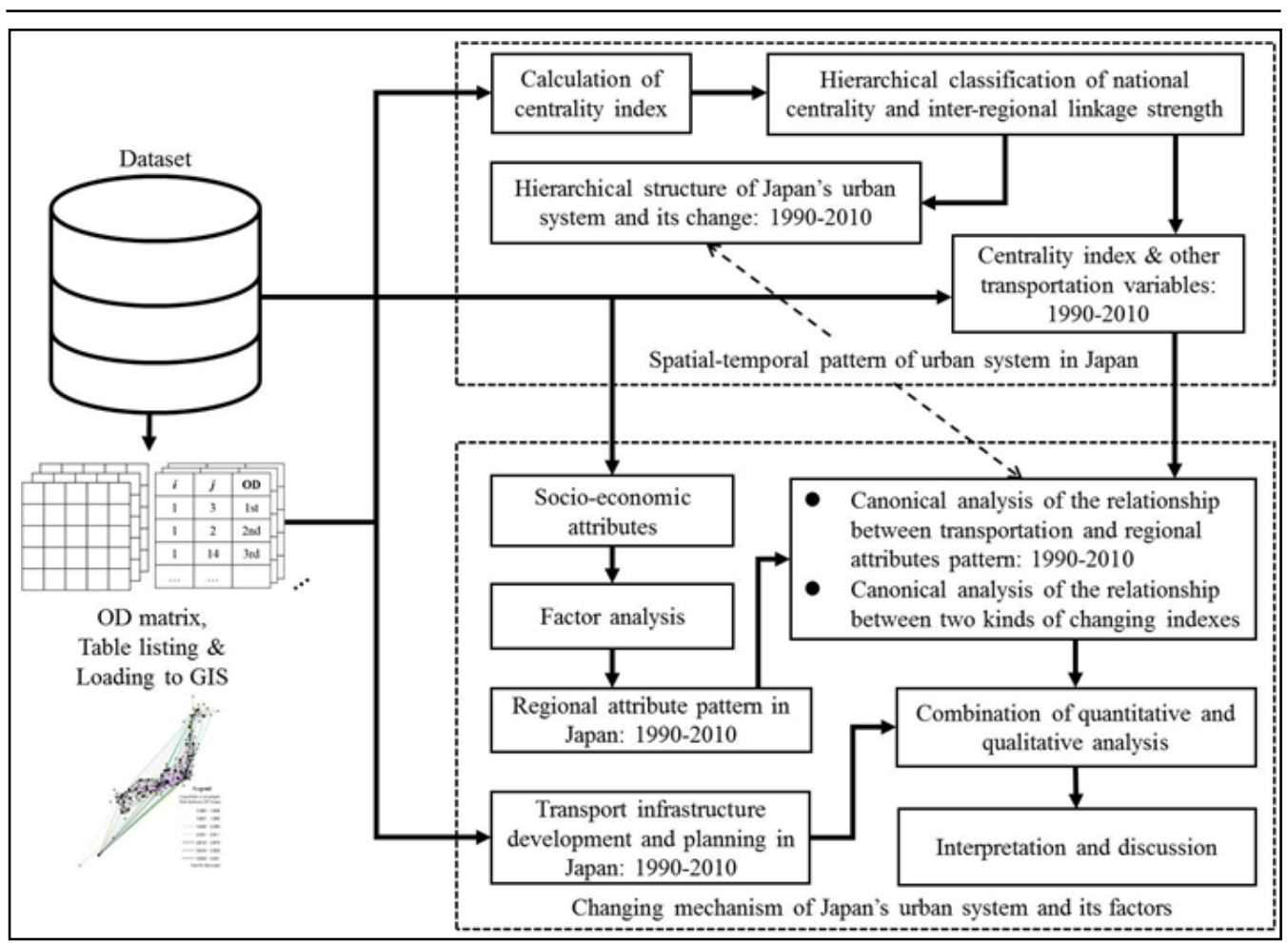

Fig. 4 - Study framework

linkage strength, the hierarchical structure of JUS and its changing patterns from 1990 to 2010 are investigated (cf. Section 3.1). At the same time, the centrality index and two other transportation variables are introduced into the next statistical model as one of the variable sets for the following canonical analysis. Next, the socio-economic attributes are entered into the factor analysis process to clarify the regional attribute pattern in Japan (Section 3.2). Fifth, canonical analysis is used to understand the relationship between transportation factors and regional attribute patterns from 1990 to 2010 and to observe the interdependency between these two kinds of changing indexes (cf. Sections 3.3 and 3.4). Finally, considering transportation infrastructure development and planning, as well as the rethinking of the actual national situation in Japan, this study makes a combination of quantitative and qualitative analyses and it provides an interpretation, discussion and conclusion to answer the final research question, i.e., revealing the changing mechanism of JUS and its factors (cf. Section 4).

Fig. 5 highlights the analysis process of the factor analysis and the canonical analysis. As Murayama (1984) noted, the regional socio-economic characteristics and inter-regional interactions are mutually associated and they are basically in a heterogeneous but analogous relationship. Therefore, the introduction of regional socio-economic factors can bring insight on the understanding of inter-cities' linkage and characterizing the pattern of urban system. Following Murayama's (1984) approaches, one of the tasks was to integrate the complicated patterns of socio-economic attributes into a small number of simple ones to deeply examine the potential spatiotemporal pattern among the socio-economic variables. In this study, through the 
factor analysis according to two matrices filled with regional attribute variables from 1990 and 2010 , a $414 \times 5$ matrix of factor scores is given. Five columns of factor scores can be seen as a set of concentrated regional attributes coming from the raw data. The 414 rows correspond to the 207 zones at two periods. Based on the results of factor analysis, the regional attribute patterns in Japan (factor scores of 1990 and 2010) and their change (subtraction of 1990's factor scores from 2010's) can be drawn in the map of Fig. 3.

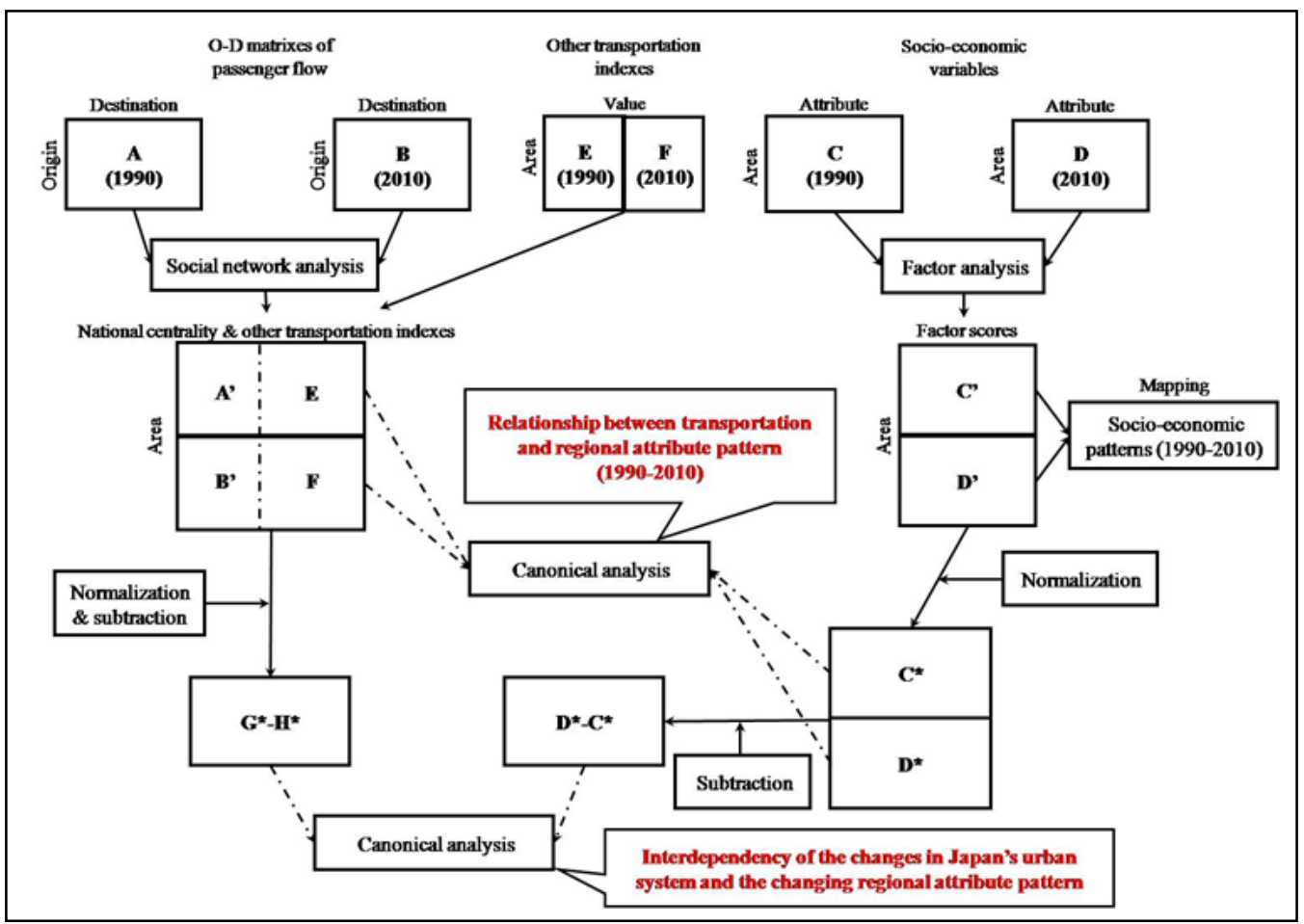

Fig. 5 - Process of factor analysis and canonical analysis

Note: $A, B, C, D$ and $E$ correspond to each matrix. A' and $B^{\prime}$ fill in the values of NC

$C^{\prime}$ and $D^{\prime}$ fill in the factor scores. $C^{*}, D^{*}, G^{*}$ and $H^{*}$ are matrices after the transformation.

Meanwhile, the social network analysis is used to consider the transportation factors within JUS. After combining the results of NC and the matrix of five other transportation indexes i.e., the ratio of business behavior, the ratio of tourism behavior, the ratio of private affairs, the proportion of daytime population to night-time population and the commuting rate outward to the prefectures (cf. Section 2.2) - the next stage is to perform the canonical analysis on two sets of normalized matrices for two times, corresponding to the relationship between the transportation factor and the regional attribute pattern at two periods (Fig. 5). In addition, using the result of subtracting 1990's matrices from 2010's matrices, the interdependency of the changes in JUS and the changing regional attribute pattern are also investigated using the canonical analysis. Herein, this study has provided an accomplishment in urban system studies under the consideration of regional attribute variables covering diverse fields by performing a variety of statistical analyses to reveal the changing mechanism of JUS and the related factors from 1990 to 2010 . 


\section{Results and Discussion}

Four parts of the results will be presented in order to better understand the results and giving the key findings. Following the study framework shown in Fig. 4, this study successfully clarified the spatiotemporal pattern of JUS and it elucidated the characteristics of change and the related factors from 1990 to 2010, by performing a series of geo-spatial multivariate analyses (cf. Section 2.4). In addition, the change mechanisms of JUS from 1990 to 2010 can be qualitatively summarized and explained based on these findings.

\section{Hierarchical structure of Japan's urban system and its change}

Table 2 shows the results of calculating the centrality index and the number of cities within each hierarchy. Comparing the results of 1990 with those of 2010, we can see that the total transportation $\left(M_{g}\right)$ increases about $36.3 \%$, the entire transport capacity $(m)$ strengthens nearly $18.2 \%$ and the number of inter-city linkages (over zero) becomes more than $15.5 \%$ higher. This proves that the development of Japan's transportation was quite remarkable from 1990 to 2010. Moreover, the Jenks natural breaks classification, regarded as a useful data clustering method designed to determine the best arrangement of values into different classes for statistical mapping (Surhone et al. 2010), is performed to identify the hierarchical structure of JUS. This classification method seeks to reduce the variance within clusters and to maximize the variance between clusters.

Hereupon, the authors divide six groups of cities within the hierarchical structure of JUS and then they show that, while the bipolarization between the higher and lower classes becomes more outstanding, the lower classes try to pursue the higher ones and to shrink the gap between them (cf. the 4th and 6th classes of Table 2). At the same time, focusing on this bipolarization phenomenon within JUS and digging up the significant evidences of it, the increase of cities in the 1st and 3rd hierarchy implies the segmentation-aggregation and uniformity-diversity of the top-class (sub)urban system (e.g., areas next to Tokyo, Nagoya, Fukuoka), as well as the coordination-independence of the secondary (2nd and 3rd class cities mainly) (sub)urban system (e.g., areas surrounding Japan's mega-cities, some regional hubcities and some emerging new-towns). In other words, the hierarchical structure of JUS tended to be more compact from 1990 to 2010 , because of the strengthening of inter-cities' linkage and the development of these sub-urban systems. This detail can be reconfirmed hereinbelow. Through the hierarchical classification of NC, this section further identifies the spatial structure

Table 2

Centrality index and the number of cities within each hierarchy

\begin{tabular}{|l|r|l|r|}
\hline \multicolumn{2}{|c|}{1990} & \multicolumn{2}{c|}{2010} \\
\hline $\boldsymbol{M}_{g}$ & 19288 & $\boldsymbol{M}_{g}$ & 26290 \\
\hline $\boldsymbol{m}$ & 319 & $\boldsymbol{m}$ & 377 \\
\hline $\boldsymbol{r}$ & 12478 & $\boldsymbol{r}$ & 14416 \\
\hline 1st & 19 & 1st & 26 \\
\hline 2nd & 35 & 2nd & 32 \\
\hline 3rd & 35 & 3rd & 45 \\
\hline 4th & 52 & 4th & 41 \\
\hline 5th & 33 & 5th & 35 \\
\hline 6th & 33 & 6th & 28 \\
\hline
\end{tabular}


of JUS and its changing patterns.

Focusing on the nodal flow, which has a $10 \%$ higher ratio of linkage amount to total amount, and the linkage among five major metropolitan areas (Tokyo, Nagoya, Osaka, Hiroshima and Fukuoka), Fig. 6 vividly illustrates the hierarchical structure of JUS in 1990 (a) and in 2010 (c), as well as it highlights its changing patterns (see sub-graphs $b$ and d) within the mathematical axis space. Colors and sizes of the dots indicate 207 cities within six hierarchical clusters. The line expresses the spatial pattern of the nodal flow and the linkage among several major metropolitan areas. For a better understanding of the changing patterns of JUS, Fig. $6 \mathrm{~b}$ and Fig. $6 \mathrm{~d}$ abstractly simulate this change. The horizontal axis means the average distance to Tokyo $^{3}$, while Tokyo is placed at the zero point. The left and right directions of the horizontal axis, respectively, correspond to the west and east of Tokyo. The vertical axis expresses the normalized value of $\mathrm{NC}^{4}$. Japan's territory can be geographically divided into seven parts. Each

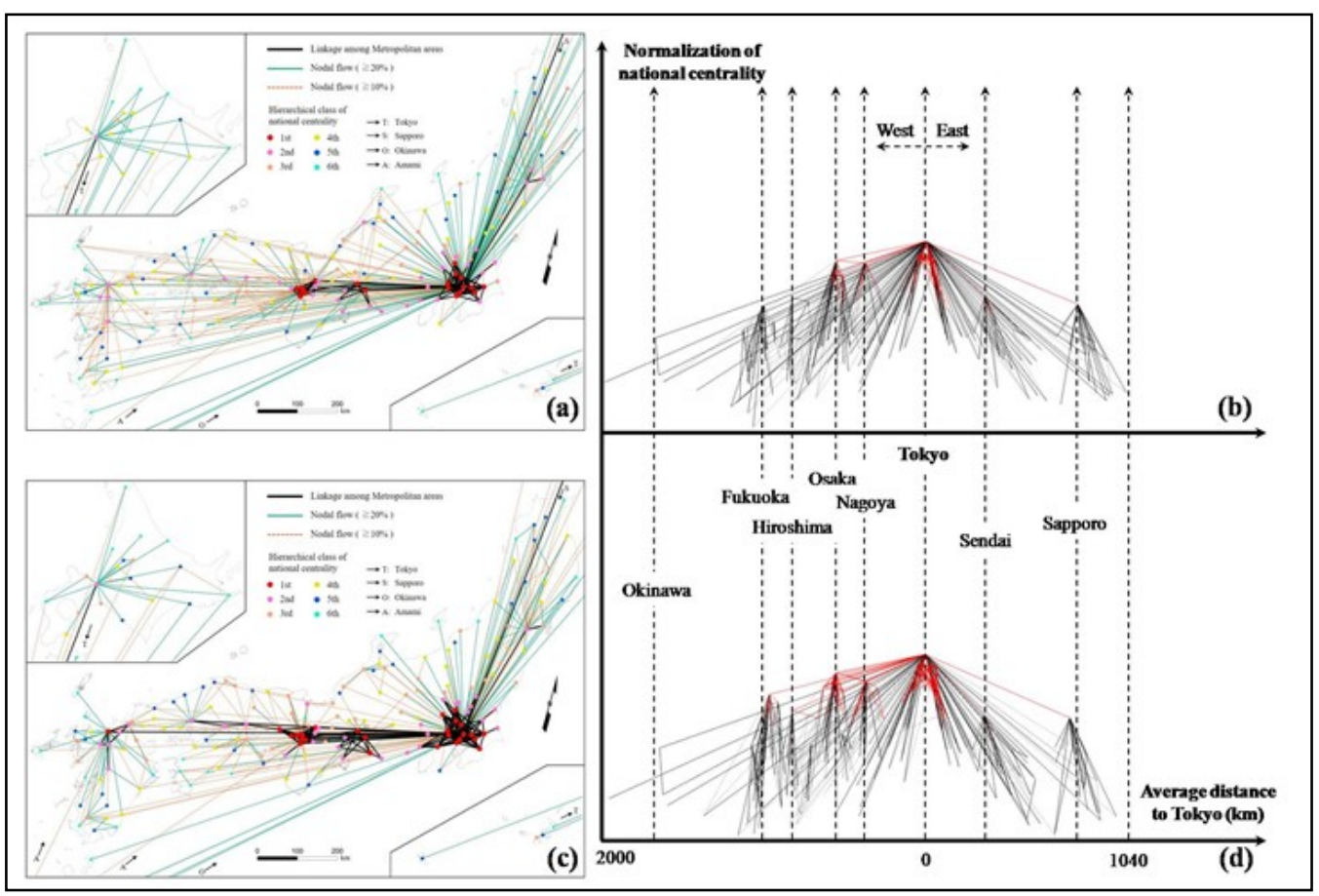

Fig. 6 - The hierarchical structure of Japan's urban system and its change (1990-2010)

part includes one or more mega-cities. Therefore, Tokyo, Nagoya, Osaka, Sendai, Hiroshima, Fukuoka, Sapporo and Okinawa are particularly shown for better understanding the change of JUS in Fig. 6.

Seven dotted lines show the datum line of seven mega-cities' relative distances toward Tokyo in 1990. Comparing Fig. 6a and Fig. 6c, meanwhile comparing Fig. 6b and Fig. 6d, this section proves several key findings as follows: 1) Nodal flows toward the metropolises are notable. In particular, Tokyo can be appointed as the leader of JUS in Japan, as nodal flows are more-orless aggregated from even the cities that are far from Tokyo, proving that JUS in 1990 was 
mononuclear. However, JUS in 2010 tends to become polycentric. The inter-city HSR system, especially that connecting to regional core cities or metropolises, has grown vigorously during 1990-2010. However, the regionally unbalanced development of transportation has brought about a serious gap between the Pacific Ocean coastal area and the Sea of Japan coastal area, as well as between the urban areas and the countryside. This detail can be supported by Fig. 3. 2) The dominance of these 8 metropolises (shown in sub-graph d) strengthens during 1990 to 2010. The linkage among the metropolitan areas becomes more obvious, especially those at Tokyo, Nagoya, Osaka, Hiroshima and Fukuoka. If combining this result with Fig. 3 , we found that the inter-city HSR system, especially that connecting to regional core cities or metropolises, has grown vigorously during 1990-2010. However, the regionally unbalanced development of transportation has brought about a serious gap between the Pacific Ocean coastal area and the Sea of Japan coastal area, as well as between the urban areas and the countryside. 3) The spatial pattern of JUS becomes compact (Fig. 6b, Fig. 6d), and the accessibility of the whole system also has an obvious increment, because the long-distance transport cost ${ }^{5}$ is substantially reduced. Fig. 3 and MLIT's white paper (MLIT 1989-2000) also implied that the development of the aviation industry has been remarkable, causing other industries, like tourism, to prosper. Moreover, the development of highways can split the transport burden with other transportation modes, can mitigate the unbalanced urbanization and can make metropolises more compact.

\section{Regional attribute patterns in Japan and their change}

This section attempts to integrate the complicated socio-economic attribute patterns into a small number of latent factors by applying the factor analysis onto the geographical matrix of $414(207 \times 2)$ rows of zone IDs and 22 columns of regional attributes (Table 1$)$. Referring to the results of the factor analysis shown in Table 3 , it can be seen that most socio-economic variables provide evidence of a high communality of over 0.70 . Five factors with high eigenvalues were obtained from the factor analysis (Table 3). These five factors account for $80.26 \%$ of the total variance. According to the high factor loadings and their corresponding implications shown in Table 3, the authors hence refer to these five factors (I to V) as follows: scale of urbanization; population growth rate; industry and commerce; agriculture and cultural facilities and tertiary industry; isolated island and airport access.

In detail, factor I reflects high loadings in many categories, like population, GDP, employment and number of railway stations, which means that this factor is strongly associated with the urban development level and scale of urbanization. While factor II displays a high negative percentage of aged people and a positive population growth rate, it is unquestionable to give the above-mentioned name. In the case of factor III, indexes about industry and commerce (e.g., Nos. 11 and 13) have a higher loading, but negative loadings in the variable: employment rate for the primary sector. Therefore, the authors identify this factor as industry and commerce. On the contrary, agricultural population and agricultural income produced present a higher loading in factor IV. Furthermore, this factor also appears to have a higher positive correlation to the number of cultural facilities. Finally, factor $V$ can be explained as the characteristics from the dominance of the tertiary industry, the isolated island situation and the advantageous airport access.

After interpreting each factor's pattern, the distribution patterns of the socio-economic attributes are mapped using the normalized factor score. Fig. 7 depicts their distributions from 1990 to 2010 , as well as their changing patterns. Referring to the thematic maps illustrated by Fig. 7 , we can clearly identify the extent of every factor displayed in every DLS zone and how its pattern changes. Dots show the central city of each DLS (this is the same as in Fig. 3). The colors of the dots express the numerical classification of the factor score. From the color's gradient and tone, the socio-economic pattern at two time periods and their changes can be 
Factor analysis of socio-economic attributes (1990-2010)

\begin{tabular}{|c|c|c|c|c|c|c|c|}
\hline \multirow{2}{*}{ No. } & \multirow{2}{*}{ Variables } & \multirow{2}{*}{ Communality } & \multicolumn{5}{|c|}{ Factor loadings } \\
\hline & & & 1 & II & III & IV & $\mathrm{V}$ \\
\hline 1 & Population & 0.96 & 0.92 & & & & \\
\hline 2 & Percentage of aged people & 0.84 & & -0.87 & & & \\
\hline 3 & Population density & 0.79 & 0.80 & & & & \\
\hline 4 & Rate of in-migrants & 0.78 & & 0.77 & & & \\
\hline 5 & Population growth rate & 0.84 & & 0.80 & & & \\
\hline 6 & Gross national income & 0.94 & 0.95 & & & & \\
\hline 7 & Number of privately-owned vehicles & 0.87 & 0.80 & & & & \\
\hline 8 & Agricultural population & 0.90 & & & & 0.93 & \\
\hline 9 & Agricultural income produced & 0.86 & & & & 0.91 & \\
\hline 10 & $\begin{array}{l}\text { Value of shipments of manufactured } \\
\text { goods }\end{array}$ & 0.63 & 0.61 & & & & \\
\hline 11 & Number of employees per factory & 0.63 & & & 0.78 & & \\
\hline 12 & Annual sales of merchandise & 0.83 & 0.89 & & & & \\
\hline 13 & Number of employees per store & 0.83 & 0.51 & & 0.55 & & \\
\hline 14 & Employment population & 0.96 & 0.93 & & & & \\
\hline 15 & $\begin{array}{l}\text { Employment rate for primary sector of the } \\
\text { economy }\end{array}$ & 0.83 & & & -0.73 & & \\
\hline 16 & $\begin{array}{l}\text { Employment rate for secondary sector of } \\
\text { the economy }\end{array}$ & 0.92 & & & & & -0.81 \\
\hline 17 & $\begin{array}{l}\text { Employment rate for tertiary sector of the } \\
\text { economy }\end{array}$ & 0.88 & & & & & 0.88 \\
\hline 18 & Number of railway stations & 0.85 & 0.92 & & & & \\
\hline 19 & Number of cultural facilities & 0.80 & 0.68 & & & 0.48 & \\
\hline 20 & Dummy variable of the isolated island & $\overline{0.49}$ & & & -0.64 & & 0.65 \\
\hline 21 & Number of highway interchanges & 0.82 & 0.88 & & & & \\
\hline 22 & Superiority of airport access & $\overline{0.41}$ & & & & & 0.48 \\
\hline \multicolumn{3}{|c|}{ Eigenvalue } & 7.75 & 2.73 & 2.61 & 2.37 & 2.20 \\
\hline \multicolumn{3}{|c|}{ Percentage of total variance } & 35.22 & 12.41 & 11.85 & 10.76 & 10.01 \\
\hline \multicolumn{3}{|c|}{ Accumulative percentage } & 35.22 & 47.64 & 59.48 & 70.25 & 80.26 \\
\hline
\end{tabular}

exhaustively read, zone by zone. To keep the data precise and consistent, the numerical classification of each category's factor score is performed using the same calibration (Fig. 7). Then, the regional attribute pattern of the whole JUS and its changes are revealed as follows.

The scale of urbanization strengthens widely but slightly, especially in the Pacific Ocean coastal area, Seto Inland Sea area and metropolises (Fig. 7a, Fig. 7b, Fig. 7c). However, urbanization declines slightly in depopulated areas like Chugoku, Shikoku and Kyushu District, and the in most isolated islands. This phenomenon can be interpreted and understood as Japan's regional imbalance of urban development levels and potential. Although a few areas near the seven major mega-cities present a slight improvement of this factor's score, the development levels of most DLS urbanizations are stagnating or even retrogressing (Fig. 7c) under the consideration and precondition of urbanization year-on-year growth in JUS.

Because of the economic crisis brought by the collapse of Japan's bubble economy in 1991, the population growth rate related to the whole of Japan slows compared to the 1980s. 
Oppositely, it increases in the suburban areas of the metropolises because of the development of suburbanization. The population growth rate in the depopulated areas may be negative (Fig. 7d, Fig. 7e, Fig. 7f). After the bubble economy, Japan witnessed a steady and slow recovery from 1990 to 2010. The results suggest that the population grew in the suburban areas in 1990 (Fig. 7d), but in 2010, it become somewhat weaker (Fig. 7e). This can also be regarded as a reflection of the development of suburbanization. The re-growth of population with high growth rates in the inner area of megacities in 1990 can also be verified (Fig. 7d), while in 2010 this trend is limited in several few metropolitan areas (Fig. 7e). If comparing with Fig. 2, we can see an astonishing proposition: the transport infrastructure development in Japan promoted more population growth and immigration, while some depopulated areas were not able to enjoy the urban resources and they reluctantly allowed their population to gradually shrink. This phenomenon is known as the "straw effect" in the context of Japan".

Except in a few areas, industry and commerce develop remarkably and become prosperous, especially in the border areas of the metropolises (Fig. 7g, Fig. 7h, Fig. 7i). To some extent, this can be considered a slight recovery from the burst of Japan's bubble economy since the 2000s. The agriculture in Japan is quickly and widely falling into decay, except in the surrounding areas of the metropolises. Additionally, the number of cultural facilities (primary schools, mainly, based on the authors' calculation) decreases, clearly because of Japan's wide depopulation (Fig. 7j, Fig. 7k, Fig. 7I). This detail further corroborates that the negative impact on agricultural productivity and primary school maintenance have been intensely influenced by these factors (e.g., depopulation, straw effect and regional imbalance).

The tertiary industry and airport access develop dramatically, especially near the areas where new airports are constructed (Fig. 7m, Fig. 7n, Fig. 7o). Considering the previous findings and the information from Fig. 2, this study confirms that Japan's recovery is remarkably associated with the development of tertiary industries, including aviation. In addition, isolated island areas are usually tied to few areas by a weak linkage (Fig. 6), and airport access seems to be their only channel to the Japanese mainland (e.g., Okinawa). This is why factor $V$ indicates higher scores in isolated island areas but it does not show an obvious increase in the patterns of change there.

\section{Relationship between transportation factors and regional attribute patterns}

After revealing the regional attribute patterns in Japan and their change by using the factor analysis, the canonical analysis is used to understand the relationship between transportation factors and regional attribute patterns from 1990 to 2010 and to observe the interdependency between these two kinds of changing indexes (Fig. 4, Fig. 5). This section attempts to reveal the relationship between transportation factors and regional attribute patterns using the canonical analysis. Moreover, the results of the canonical analysis provide rich hints that can be linked with the verification of exploratory hypotheses. Following the process mentioned in Section 2.4, the authors present the results in Fig. 8.

The descriptions of $Y_{1}$ to $Y_{6}$ (transportation factors) and $X_{1}$ to $X_{5}$ (factor scores of regional attributes) are defined as follows: $Y_{1}$ is national centrality; $Y_{2}$ is the ratio of business behavior; $Y_{3}$ is the ratio of tourism behavior; $Y_{4}$ is the ratio of private affairs or homecoming behavior; $Y_{5}$ is the proportion of daytime population to night-time population; $Y_{6}$ is the commuting rate outward to the prefectures; $X_{1}$ is the scale of urbanization; $X_{2}$ is the population growth rate; $X_{3}$ is industry and commerce; $X_{4}$ is agriculture and cultural facilities; $X_{5}$ is tertiary industry, isolated island and airport access. Though viewing two sets of canonical variables on three or two levels - i.e., $U^{*}$ and $V^{*}$, autocorrelation within groups of $Y_{1}$ to $Y_{6}$ and $X_{1}$ to $X_{5}$ - the canonical correlation between them can be determined. From the structural equation highlighted at the bottom of each sub-graph and the arrows from the original variable factor $\left(Y^{*}\right.$ and $\left.X^{*}\right)$ toward each canonical variable $\left(\mathrm{U}^{*}\right.$ and $\left.\mathrm{V}^{*}\right)$, the factor loadings against the canonical variable pairs 


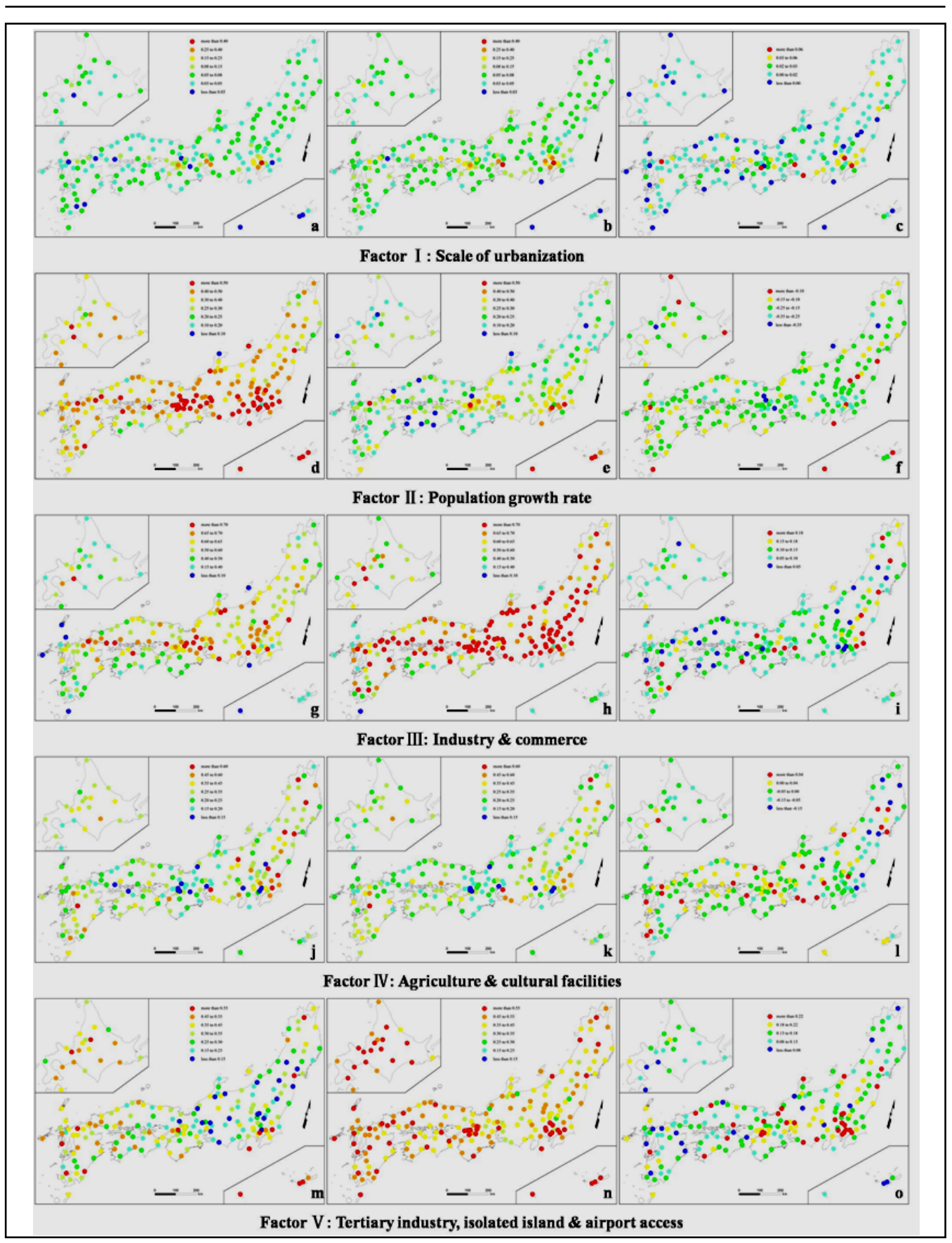

Fig. 7 - Factor score distributions of socio-economic attributes from 1990 (left) to 2010 (middle) and their changing patterns (right) 
can also be checked in detail; this implies cross influence among them. Four canonical vectors are obtained for 1990, and three for 2010, at the 0.01 level of confidence. In-group correlation coefficients (dotted lines) can also be read, which indicate the scale of collinearity between the variables.

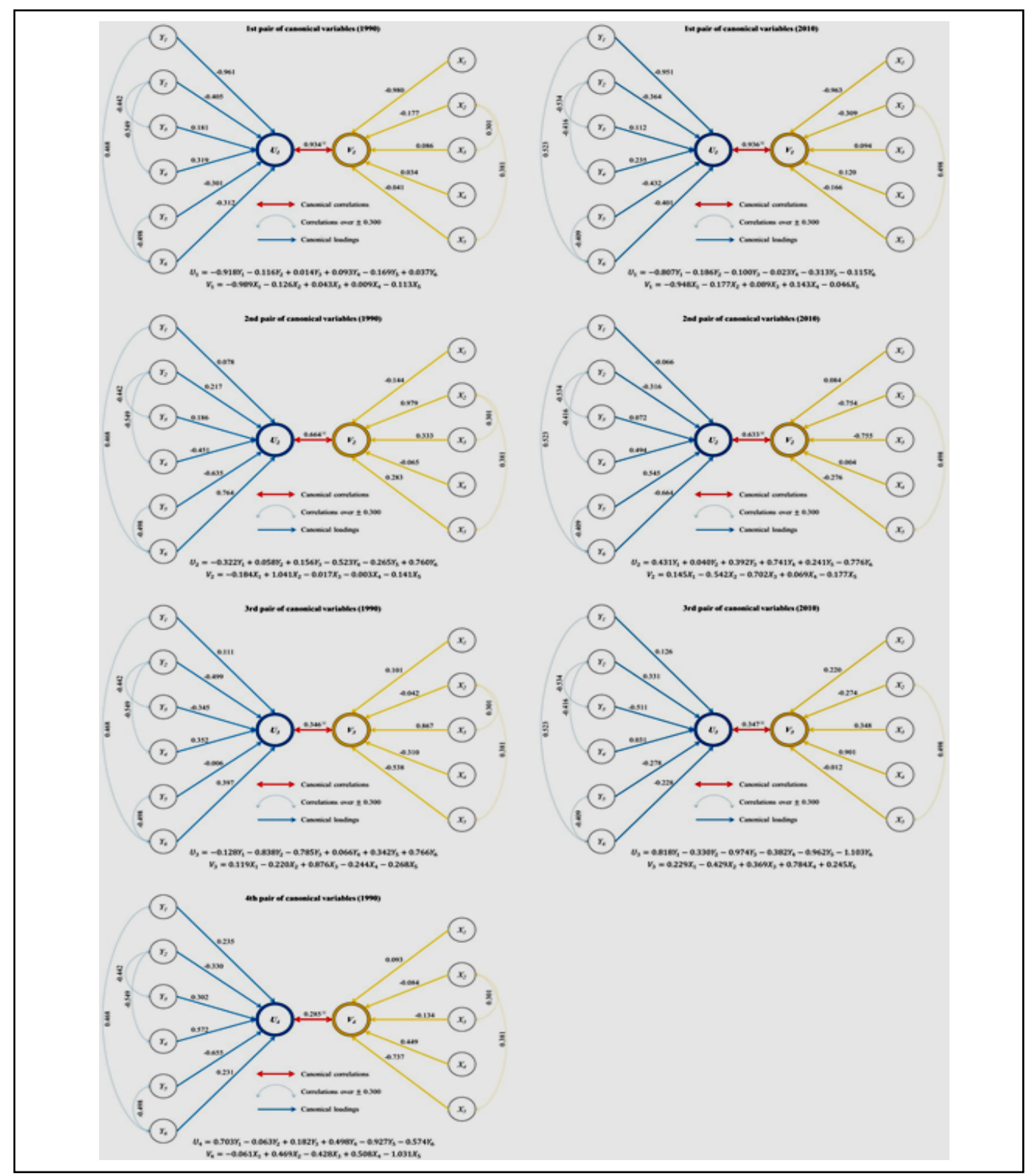

Fig. 8 - Canonical analyses of the relationship between the transportation factor and DLS's attribute pattern in 1990 (left) and 2010 (right) Note: *Significant at the 0.01 level of confidence (same as Fig. 9) 
Overall, the results prove the following: 1) The 1st pair of canonical variables in both 1990 and 2010, as the highest canonical correlation between $Y$-set and $X$-set, implies that $Y_{1}$ has a strong positive correlation against $X_{1}$ because its canonical loadings are high and have the same sign. This reveals that the dominance of urbanization has a strong and mutual effect with the national centrality. This sequitur can also be proven from $Y_{2}$ and $Y_{5}$ and $Y_{6}$ toward $X_{2}$. Moreover, from $Y_{3}$ and $Y_{4}$ and $X_{3}$ and $X_{4}$, we find some weak positive correlations. This proves that tourism, private affairs or homecoming behavior, as well as the prosperity of industry, commerce, agriculture and culture may affect each other significantly. On the contrary, it is clear that $Y_{3}$ and $Y_{4}$ have a negative correlation against $X_{1}$, which means that urbanization may restrain tourism, private affairs or homecoming behaviors; 2) Similarly, the remaining canonical variable pairs can also be used to find the hidden relationships among the variables, as well as to discover the key arguments. Considering the second pair of canonical variables in $1990, Y_{2}$, $Y_{5}$ and $Y_{6}$ have strong positive correlations against $X_{2}, X_{3}$ and $X_{5}$, which reveals that the development of secondary industry, commerce, tertiary industry, airport access and population growth have effects from (or on) the remarkableness of business behavior, day-night population diversity and long-distance commuting rates. Moreover, $Y_{4}$ and $Y_{5}$ have negative correlations against $X_{2}$ and $X_{3}$. Indeed, this is a kind of antithetical effect among the variables in the second canonical variable pair. This shows their opposite relationship to each other. 3 ) Considering the case of 2010, we found that the results vary in the changing indexes and it is not easy to compare the results between 1990 and 2010. At a minimum, the results from 2010 are generally consistent with the ones from 1990, except regarding $Y_{5}$. Unlike the case of 1990, the relationships between the day-night population diversity and the development of secondary industry, commerce and tertiary industry and population growth become negative correlations. It can be regarded as a phenomenon of the changing JUS, which will be considered in the next section. 4) Simply stated, the urban functions and the characteristics of transportation experienced a remarkable change during the period from 1990 to 2010 . Considering the low correlation values of the third and fourth canonical variable pairs $(<0.4)$, discussions of these categories are omitted here.

\section{Interdependency of the changes in Japan's urban system and the changing regional attribute patterns}

The same analyses performed in Section 3.3 are performed between the changing values of $Y$ set and of X-set to highlight the interdependency of the changes in JUS and the changing regional attribute patterns. Accompanying the findings from Sections 3.1 and 3.2, the kinds of places where the centrality index and the socio-economic features changed can be discussed together. Considering that the study's purpose is highlighting and elucidating the change mechanisms of JUS and the related factors, however, sometimes the results of the canonical analysis could not explain all changes or match the findings grasped in a simple way of visualization. This is because a country's mechanisms of change are quite complex, uncontrolled and highly random, with collinearity and regional bias. Moreover, it is difficult to unilaterally explain using the quantitative model. Therefore, in this section, this study confirms and it verifies some passable hypotheses based on the analyses and it further provides a qualitative interpretation supporting the whole study (Fig. 10).

In brief, the changes in national centrality $\left(Y_{1}\right)$ and in day-night population diversity $\left(Y_{5}\right)$ have positive correlations against the changes in urbanization $\left(X_{1}\right)$ and in tertiary industry and airport access $\left(X_{5}\right)$, following the general situation. Additionally, the change in the long-distance commuting rate $\left(Y_{6}\right)$ has a negative correlation against the changes in industry and commerce $\left(X_{3}\right)$. This can be understood as, for example, a place that has a remarkable industry and commerce may not have a high commuting rate outward to the prefectures, and vice versa. The same results can also be seen between $Y_{1}$ and $X_{3}$. Conversely, the changes in day-night population diversity $\left(Y_{5}\right)$ have a positive correlation against the changes in industry and 


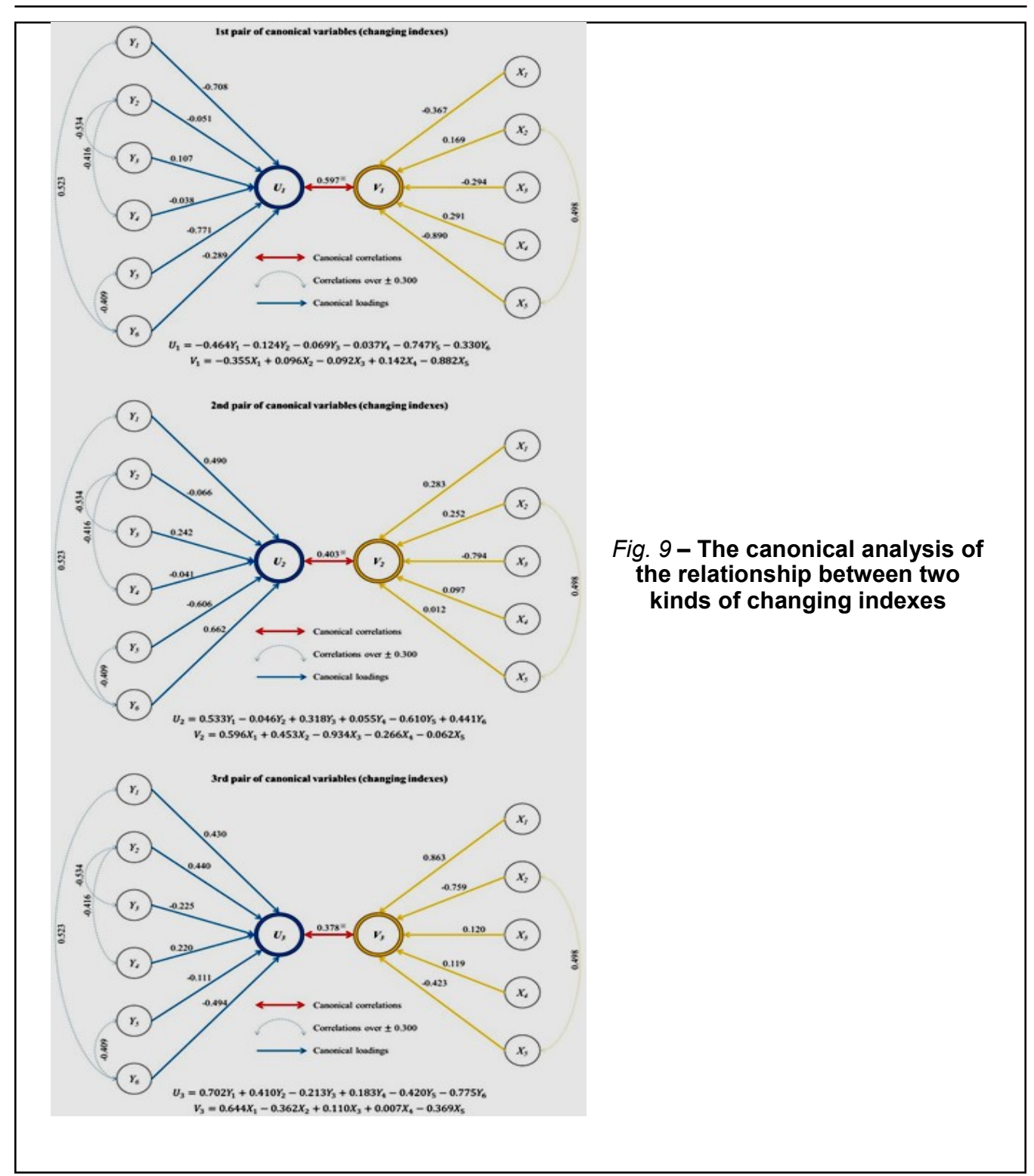

commerce $\left(\mathrm{X}_{3}\right)$, as the place with highly developed industry and commerce may tend to attract

a larger commuting population. Finally, the changing ratio of tourism behavior $\left(\mathrm{Y}_{3}\right)$ and the changing long-distance commuting rate $\left(\mathrm{Y}_{6}\right)$ have positive correlations against the changing population growth rate $\left(X_{2}\right)$ and the changes in tertiary industry and airport access $\left(X_{5}\right)$, but they have negative correlations against the changing scale of urbanization $\left(\mathrm{X}_{1}\right)$. This is because more tourism and external commuting activities tend to promote population growth, as well as the development of tertiary industry and airport access. However, it can also 
simultaneously cause counter-urbanization and depopulation to some extent, as mentioned in Section 3.2.

\section{Conclusions}

This study aims to clarify the spatiotemporal pattern of the urban system in Japan and then to highlight and to elucidate the changing mechanisms of JUS and the related factors. Based on the inter-regional travel survey conducted in Japan from 1990 to 2010 (MLIT 1990, 2010) and on the numerous other official censuses, the hierarchical structure of JUS is constructed. After that, a series of analyses were performed to reveal the regional attribute patterns, understanding the relationship between the transportation factors and the regional attribute patterns from 1990 to 2010 and lastly discussing the interdependency of the changes in JUS and the changing regional attribute patterns. The results prove that the changes have taken place in terms of the entire system's compactness, the metropolises' dominance and the local systems' bipolarization under the hierarchical structure of JUS, with the establishment of hub cities during the post-war high economic growth period and the development of infrastructure during the two decades in question.

The change mechanisms of JUS, with consideration of socio-economic characteristics and inter-regional interactions, are qualitatively summarized and explained in Fig. 10. In summary, owing to the progress of urbanization, the development of transport infrastructure and the development of aviation and tertiary industry, the dominance of metropolises has been remarkably enhanced, causing JUS to become more compact and the inter-regional interactions among cities to strengthen. At the same time, three major industries tend to be developed and promoted toward the outer edges of the metropolises. Although this can bring about some favorable circumstances in some areas, the industry recession and the decreasing population become profound in the depopulated areas, which can be regarded as the so-called

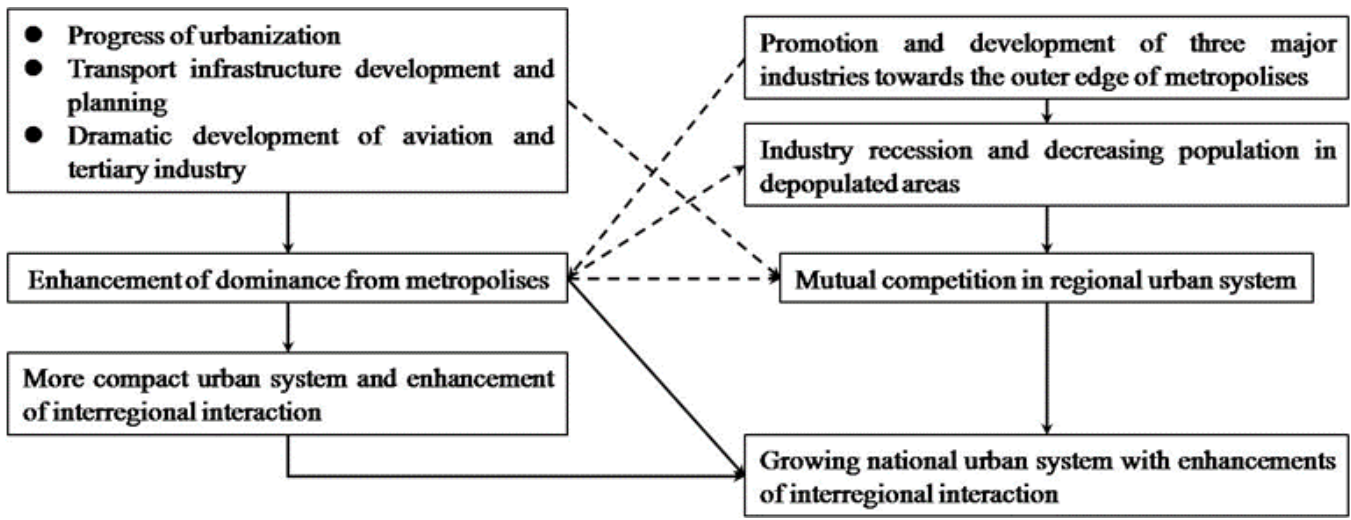

Fig. 10 - Change mechanisms of Japan's urban system from 1990 to 2010

"straw effect" in Japanese. Additionally, mutual competition in regional urban systems can be considered while the compact national system takes shape. Accordingly, JUS is generally a growing national urban system, with the enhancements of inter-regional interaction.

Overall, this study would have been valuable even if it only measured the hierarchical structure of JUS and its changing patterns. The exploratory analysis of what might be associated with the changes in JUS's hierarchical structure may also be useful for building hypotheses; to a 
certain extent, the achievement of this study can serve as the case of a kind of exploredhypothesis verification. Considering about the originality that can be confirmed in this study, performing multi-view studies that considered the issue of the urban system on a uniform scale by the way of introducing reasonable factors to explain the pattern within the urban system's mutual feedback mechanism, not just those resting on constructing this pattern itself like most previous studies, have brought some unknown research interests. This study also provided an examination of the changing processes of JUS and the related factors, with consideration for the socio-economic features, aiming to fill the research gaps mentioned in Section 1.

Considering about the research limitation, explaining the causes of the changes seems quite ambitious and valuable, which means that a more rigorous approach should be taken to deeply explore the explanations for these changing mechanisms. Moreover, the description of Japanese policies and the transport infrastructure development and its association with the pattern of JUS are not fully explained in this context, which means that more future studies should be done for linking the findings of this study towards the previous studies and for providing academic verification to the MLIT's document.

As a consequence, this study is an accomplishment in urban system studies. Furthermore, in this research, the authors introduce regional attribute variables covering diverse fields population, economy, transportation, industrial composition, human facility, etc. - as a research innovation compared to previous studies. Through a series of geo-spatial multivariate analyses, the changes in JUS and their factors are successfully addressed. Not only researchers and scholars, but also urban planners and the general public can find material to suit their interests, arguments and reference needs. This study possesses the value of providing guidance for urban planning optimization and urban development sustainability in the context of Japan.

\section{Acknowledgements}

The authors sincerely take this opportunity to express special thanks to the academic supervisor, Prof. Yuji Murayama. Other people also guided us in important ways, including Prof. Toshiaki Ichinose, and Assistant Professor Takehiro Morimoto. The Ministry of Land, Infrastructure and Transport (Japan) provided the raw GIS and statistical data needed in this research.

\section{Notes}

1. Kakuei Tanaka, Japanese Prime Minister (1972-1974), proposed the "Plan for Remodeling the Japanese Archipelago" in 1972, to promote the development of land in Japan.

2. The Prefectures of Japan (Todoffuken) consist of 47 prefectures, forming the first level of administrative division in Japan. Each prefecture consists of numerous municipalities. There are four types of municipalities in Japan: cities, special wards, towns and villages. In Japanese, this system is known as Shikuchōson.

3. This study calculates the average distance $\left({ }^{\bar{d}}\right)$ from city $i$ to Tokyo based on the utilization ratio of three different major transportation modes as its weighted values, across multiple times at different distances. Its equation is defined as follows:

$$
\bar{d}=\alpha_{c} d_{1}+\beta_{c} d_{2}+\gamma_{c} d_{3}
$$

case $\{d<100 ; 100 \leq d<200 ; 200 \leq d<300 ; 300 \leq d<500 ; 500 \leq d<750 ; 750 \leq d<1000$ and $d \geq 1000\}$,

where $d_{1}, d_{2}$ and $d_{3}$ are the distance $(\mathrm{km})$ by train, automobile and airplane, respectively. $\alpha, \beta$ and $\gamma$ express their corresponding utilization ratios. Moreover, $c$ indicates eight 
distance cases of the line distance $(d)$ from city $i$ toward Tokyo: $d<100 ; 100 \leq d<200$; $200 \leq d<300 ; 300 \leq d<500 ; 500 \leq d<750 ; 750 \leq d<1000$ and $d \geq 1000$. $\alpha, \beta$ and $\gamma$ in these cases are defined and published by the MLIT (2010).

4. In this study, the equation of normalization of national centrality $\left({ }^{N_{i}^{*}}\right)$ is calculated as follows:

$$
\begin{gathered}
N_{i}^{*}=\frac{N_{i}^{s}-\min \left\{N_{i}^{s}\right\}}{\max \left\{N_{i}^{s}\right\}-\min \left\{N_{i}^{s}\right\}}+\varepsilon \\
N_{i}^{s} \in\left\{\operatorname{Ln}\left(N_{i}\right)\right\}, i \in[1,207], N_{i}^{*} \in(0,1], \varepsilon \rightarrow 0 \text { and } \varepsilon>0
\end{gathered}
$$

5. According to MLIT (2010), the long-distance transport cost is defined as the one over $750 \mathrm{~km}$. The meaning of "straw effect" in Japanese can be found in the website of Wikipedia, https://ja.m.wikipedia.org/wiki/ストロー効果

\section{References}

AUTOMOBILE INSPECTION AND REGISTRATION INFORMATION ASSOCIATION OF JAPAN (1990 and 2010), Statistics of Privately Owned Vehicles, AIRIA, Retrieved from: www.airia.or.jp.

BURGHOUWT G., HAKFOORT J., VAN ECK J. R. (2003), The spatial configuration of airline networks in Europe, Journal of Air Transport Management 9 (5), 309-323.

CHOI J. H., BARNETT G. A., CHON B.-S. (2006), Comparing world city networks: a network analysis of Internet backbone and air transport intercity linkages, Global Networks 6 (1), 81-99.

CENTER FOR SPATIAL INFORMATION SCIENCE (2015), Need for Urban Area Definition, CSIS. University of Tokyo, Retrieved from: www.csis.u-tokyo.ac.jp.

DERUDDER B., TAYLOR P. J., HOYLER M., NI P., LIU X., ZHAO M., SHEN W., WITLOX F. (2013), Measurement and interpretation of connectivity of Chinese cities in world city network, 2010, Chinese Geographical Science 23 (3), 261-273.

DERUDDER B., TAYLOR P. J., WITLOX F., CATALANO G. (2003), Hierarchical tendencies and regional patterns in the world city network: a global urban analysis of 234 cities, Regional Studies 37 (9), 875-886.

DERUDDER B., WITLOX F., TAYLOR P. J. (2007), U.S. cities in the world city network: Comparing their positions using global origins and destinations of airline passengers, Urban Geography 28 (1), 74-91.

DONG C., XIU C., WEI Y. (2014), Network structure of 'space of flows' in Jilin Province based on telecommunication flows, Acta Geographica Sinica 69 (4), 510-519.

GOVERNMENT OF JAPAN (1990, 2010), Report on Prefectural Accounts, Retrieved from: www.cao.go.jp.

GUIMERÀ R., MOSSA S., TURTSCHI A., AMARAL L. A. N. (2005), The worldwide air transportation network: Anomalous centrality, community structure, and cities' global roles, PNAS 102 (22), 7794-7799.

GUO W. J., BAI M. Y. (1999), A positive research on the functional hierarchy of urban air transportation and the features of air transportation relationship in China, Human Geography 14 (1), 27-31.

JOHNSTON R. J. (1982), The American Urban System, Longman, London.

LEE H.-S. (2008), The structure of the international air network through the social network analysis, Journal of Geography 117 (6), 985-996.

LENG B., YANG Y. C., LI Y., ZHAO S. (2011), Spatial characteristics and complex analysis: a perspective from basic activities of urban networks in China, Acta Geographica Sinica 66 (2), 199-211.

LU L., LI Y. (2010), A research on Chinese renovation urban system based on urban renovation function, Acta Geographica Sinica 65 (2), 177-190. 
MARTINUS K., SUZUKI J., BOSSAGHZADEH S. (2019), Agglomeration economies, interregional commuting and innovation in the peripheries, Regional Studies 54 (6), 776-788.

MATTHIESSEN C. W., SCHWARZ A. W., FIND S. (2010), World cities of scientific knowledge: Systems, networks and potential dynamics. An analysis based on bibliometric indicators, Urban Studies 47 (9), 1879-1897.

MINISTRY OF AGRICULTURE, FORESTRY AND FISHERIES OF JAPAN (1990,

2010), Statistics of Agricultural Income Produced, MAFF, Retrieved from: www.maff.go.jp. MINISTRY OF ECONOMY, TRADE AND INDUSTRY OF JAPAN $(1990,2010)$, Census of Manufactures, METI, Retrieved from: www.meti.go.jp. MINISTRY OF ECONOMY, TRADE AND INDUSTRY OF JAPAN (1994, 2007), Census of Commerce, METI, Retrieved from: www.meti.go.jp. MINISTRY OF INTERNAL AFFAIRS AND COMMUNICATIONS OF JAPAN (1990, 2010a), Basic Resident Register, MIC, Retrieved from: www.soumu.go.jp. MINISTRY OF INTERNAL AFFAIRS AND COMMUNICATIÖNS (1990, 2010b), Statistics of Japan, MIC, Retrieved from: www.stat.go.jp. MINISTRY OF LAND, INFRASTRUCTURE AND TRANSPORT OF JAPAN (19892000), Land, Infrastructure and Transport White Paper, MLIT, Retrieved from: www.mlit.go.jp. MINISTRY OF LAND, INFRASTRUCTURE AND TRANSPORT OF JAPAN (1990), 1990 inter-regional travel survey in Japan, MLIT, Retrieved from: www.mlit.go.jp. MINISTRY OF LAND, INFRASTRUCTURE AND TRANSPORT OF JAPAN (2010), 2010 inter-regional travel survey in Japan, MLIT, Retrieved from: www.mlit.go.jp. MORIKAWA H. (1998), Urbanization and Urban System in Japan, Taimeido, Tokyo. MURAYAMA Y. (1982), Canadian urban system and its evolution process in terms of air -passenger flows, Geographical Review of Japan 55 (6), 380-402.

MURAYAMA Y. (1984), Regional structure of Japanese commodity flows: an approach of geographical field theory, Annals of the Association of Economic Geographers 30 (2), 95111.

MURAYAMA Y. (2000), Japanese Urban System, Springer, London.

NISHIHARA J. (1994), Inter-urban linkages and systems of cities: the case of wholesaling activity in Kyushu province, Japan, Geographical Review of Japan Ser. A 67 (6), 357-382.

NOJIRI W. (1993), The patterns of freight flows carried by railway containers and regular road hauliers in Japan, Annals of the Association of Economic Geographers 39 (2), 136 -154 .

SMITH D. A., TIMBERLAKE M. F. (2001), World city networks and hierarchies, $1977-$ 1997: an empirical analysis of global air travel links. American Behavioral Scientist 44 (10), 1656-1678.

SONG W., LI X.-W., XIU C.-L. (2008), Patterns of spatial interaction and hierarchical structure of Chinese cities based on intercity air passenger flows, Geographical Research 27 (4), 917-926.

SUN H. (2016), Study on the correlation between the hierarchical urban system and high-speed railway network planning in China, Frontiers of Architectural Research 5 (3), 301318.

SURHONE M. L., TENNOE T. M., HENSSONOW F. S. (2010), Jenks Natural Breaks Optimization, Betascript Publishing, Riga. York.

TAYLOR P. J. (2004), World City Network: A Global Urban Analysis, Routledge, New

WANG C. (2010), Identification of inter-urban container transport hubs and their spatial characteristics: a case study of railway transportation in China, Acta Geographica Sinica 65 (10), 1275-1286.

WANG J., WANG H., JIAO J. (2015), China's international aviation transport to the Belt and Road Initiative area, Progress in Geography 34 (5), 554-562. 
WANG M.-J., ZHANG X.-X., QI Y.-J. (2005), On the evolving process of urban system in Shandong Province in the last 50 years: a study based on urban centrality, Geographical Research 24 (3), 432-442.

YAO Y., LIU Y., WANG G., DONG Y., WANG H. (2018), Relations between global city connectivity of the primary city and the size national economy, Journal of Urban and Regional Analysis 10 (1), 5-23.

YOKURA Y. (2016), Shifting centrality and connectivity of major cities in Japanese urban system through assigned functions of corporate offices, Geographical Sciences 71 (1), 19-32.

YU T.-F., GU C.-L., LI Z.-G. (2008), China's urban systems in terms of air passenger and cargo flows since 1995, Geographical Research 27 (6), 1407-1418.

ZHEN F., WANG B., CHEN Y. (2012), China's city network characteristics based on social network space: an empirical analysis of Sina micro-blog, Acta Geographica Sinica 67 (8), 1031-1043.

ZHOU C., ZENG G., MI Z., XIAN G. (2017), The study of regional innovation network patterns: evidence from the Yangtze River Delta urban agglomeration, Progress in Geography 36 (7), 795-805

Initial submission: 03.11.2019

Revised submission: 11.06 .2020

Final acceptance: 22.06 .2020

Correspondence: Fuzhou-Kanazawa University International Joint Laboratory of Spatial Planning and Sustainable Development, Fuzhou University, 2 Xue Yuan Road, Fuzhou 350116, China

Email: liukai890208@staff.kanazawa-u.ac.jp 
